\title{
ATP- and Adenosine-Mediated Signaling in the Central Nervous System: Adenosine Stimulates Glutamate Release From Astrocytes via $A_{2 a}$ Adenosine Receptors
}

\author{
Tomoyuki Nishizaki ${ }^{1}{ }^{1 *}$ \\ ${ }^{1}$ Department of Physiology, Hyogo College of Medicine, 1-1 Mukogawa-cho, Nishinomiya 663-8501, Japan
}

Received November 7, 2003; Accepted December 2, 2003

\begin{abstract}
Adenosine enhanced intracellular $\mathrm{Ca}^{2+}$ concentrations in astrocytes via $\mathrm{A}_{2 \mathrm{a}}$ adenosine receptors involving protein kinase A (PKA) activation. The $\mathrm{Ca}^{2+}$ rise is inhibited by brefeldin A, an inhibitor of vesicular transport; but not by neomycin and U73122, phospholipase C inhibitors; xestospongin, an $\mathrm{IP}_{3}$-receptor inhibitor; ryanodine, a ryanodine-receptor inhibitor; TMB-8, an endoplasmic reticulum calcium-release blocker; octanol, a gap-junction inhibitor; or cadmium, a non-selective, calcium-channel blocker. Adenosine stimulates astrocytic glutamate release via an $\mathrm{A}_{2 \mathrm{a}}$ adenosine receptors/PKA pathway, and the release is inhibited by the vesicular transport inhibitors brefeldin $\mathrm{A}$ and bafilomycin A1. $\mathrm{A}_{2 \mathrm{a}}$ adenosine receptors and the ensuing PKA events, thus, are endowed with vesicular $\mathrm{Ca}^{2+}$ release from an unknown intracellular calcium store and vesicular glutamate release from astrocytes.
\end{abstract}

Keywords: adenosine, $\mathrm{A}_{2 \mathrm{a}}$ receptor, glutamate release, $\mathrm{Ca}^{2+}$, astrocyte

A new neuromodulatory pathway with a glial contribution mediated via $A_{2 a}$ adenosine receptors

Several lines of evidence have pointed to direct communications between neurons and astrocytes. Astrocytes express a wide range of receptors and respond to synaptically released neurotransmitters released from presynaptic terminals (1). Astrocytes, alternatively, release neurotransmitters in response to an increase in intracellular $\mathrm{Ca}^{2+}$ concentrations, which in turn stimulates neurons $(2-6)$. A low concentration $(10 \mathrm{nM})$ of adenosine facilitates hippocampal neurotransmission, where adenosine does not affect synaptically released glutamate and GABA or postsynaptic glutamatergic and GABAergic conductances (7). Adenosine, on the other hand, inhibits functions of the astrocytic glutamate transporter GLT-1 and stimulated glutamate release via $\mathrm{A}_{2}$ adenosine receptors involving protein kinase $\mathrm{A}$ (PKA) activation (7). Those actions could enhance synaptic glutamate concentrations, responsible for the facilitatory action of adenosine on hippocampal neurotransmission. Adenosine, thus, modulates hippocampal

*Corresponding author. FAX: +81-798-45-6649

E-mail: tomoyuki@hyo-med.ac.jp neurotransmission by targeting astrocytes.

Intracellular $\mathrm{Ca}^{2+}$ rise in astrocytes via $\mathrm{A}_{2 \mathrm{a}}$ adenosine receptors

Adenosine $(10 \mathrm{nM})$ increases astrocytic intracellular $\mathrm{Ca}^{2+}$ concentrations in $\mathrm{Ca}^{2+}$-containing and -free extracellular solution, indicating that adenosine stimulates $\mathrm{Ca}^{2+}$ release from intracellular $\mathrm{Ca}^{2+}$ stores in astrocytes (7). The $\mathrm{Ca}^{2+}$ rise is inhibited by 3,7-dimethyl-1propargylxanthine (DMPX), an antagonist of $\mathrm{A}_{2}$ adenosine receptors, or H-89, a selective inhibitor of PKA (7). This suggests that the intracellular $\mathrm{Ca}^{2+}$ rise is regulated via an $A_{2 a}$ adenosine receptors/PKA pathway. In further support of this idea, the $\mathrm{A}_{2}$ adenosine receptor agonist CGS21680 enhances intracellular $\mathrm{Ca}^{2+}$ concentrations in astrocytes, and the effect is inhibited by DMPX or H-89 (Fig. 1). Surprisingly, brefeldin A, an inhibitor of vesicular transport, inhibits the CGS21680 action (Fig. 1). This, taken together with the fact that the intracellular $\mathrm{Ca}^{2+}$ rise is not affected by the phospholipase $\mathrm{C}$ inhibitors neomycin and $\mathrm{U} 73122$, the $\mathrm{IP}_{3}$-receptor inhibitor xestospongin, the ryanodine-receptor inhibitor ryanodine, the endoplasmic reticulum (ER) calciumrelease blocker TMB-8, the gap-junction inhibitor 

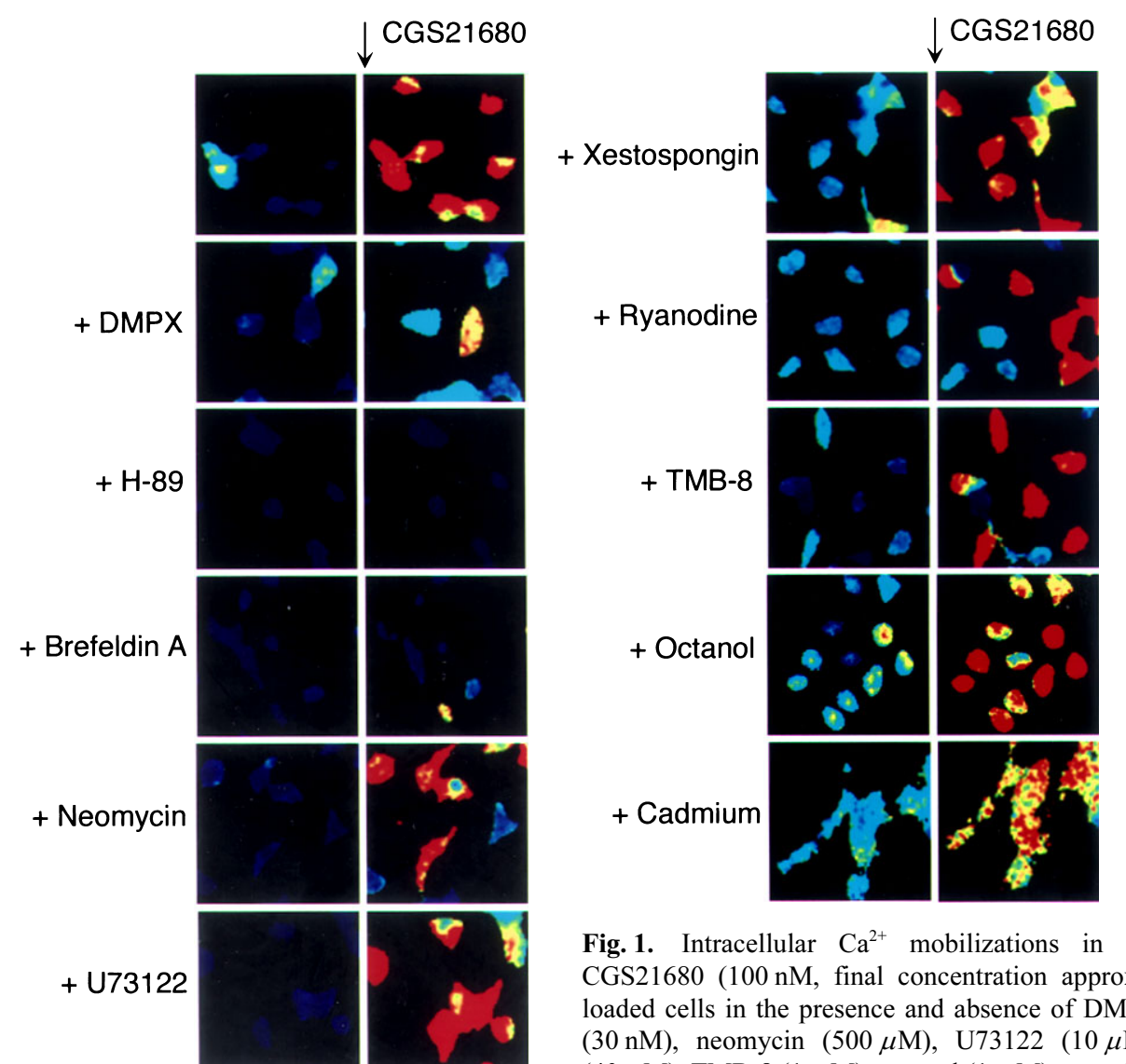

Fig. 1. Intracellular $\mathrm{Ca}^{2+}$ mobilizations in cultured rat hippocampal astrocytes. CGS21680 (100 nM, final concentration approx. $10 \mathrm{nM})$ was bath-applied to fura-2loaded cells in the presence and absence of DMPX $(10 \mu \mathrm{M}), \mathrm{H}-89(5 \mu \mathrm{M})$, brefeldin A $(30 \mathrm{nM})$, neomycin $(500 \mu \mathrm{M})$, U73122 $(10 \mu \mathrm{M})$, xestospongin $(50 \mu \mathrm{M})$, ryanodine (40 $\mu \mathrm{M})$, TMB-8 (1 mM), octanol (1 mM), or cadmium $(200 \mu \mathrm{M})$.

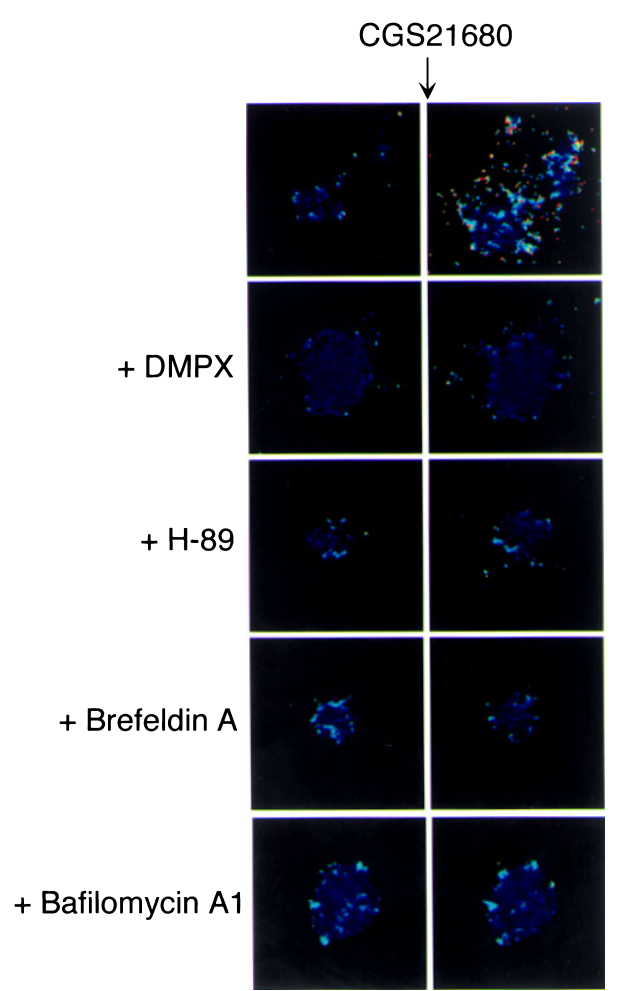

Glu release

$(+)$

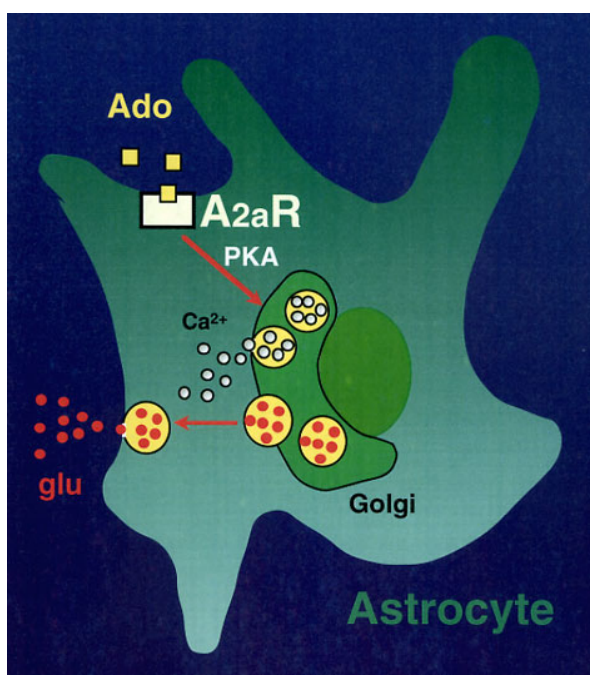

Fig. 3. Diagram for astrocytic glutamate release via an $A_{2 a}$ adenosine receptor/PKA signaling pathway. $\mathrm{A}_{2 \mathrm{a}} \mathrm{R}, \mathrm{A}_{2 \mathrm{a}}$ adenosine receptors; Ado, adenosine; glu, glutamate.

Fig. 2. Glutamate release from cultured rat hippocampal astrocytes. Glutamate released from astrocytes was detected by using an enzymatic assay. L-Glutamic dehydrogenase (GDH) reduces $\beta$-nicotinamide adenine dinucleotide $\left(\mathrm{NAD}^{+}\right)$to $\mathrm{NADH}$, which fluorescences when excited with $\mathrm{UV}$, in parallel with a reaction from glutamate to $\alpha$-ketoglutarate. NADA fluorescence, therefore, is used an indirect indicator of glutamate level. CGS21680 (approx. $10 \mathrm{nM}$ ) was bath-applied to cells in the presence and absence of DMPX $(10 \mu \mathrm{M}), \mathrm{H}-89(5 \mu \mathrm{M})$, brefeldin $\mathrm{A}(30 \mathrm{nM})$, or bafilomycin $\mathrm{A} 1(4 \mu \mathrm{M})$. 
octanol, or the non-selective calcium channel blocker cadmium (Fig. 1), raises the possibility that $A_{2 a}$ adenosine receptors and the ensuing PKA events bear vesicular $\mathrm{Ca}^{2+}$ release from an as yet unidentified intracellular $\mathrm{Ca}^{2+}$ store in astrocytes.

\section{Glutamate release from astrocytes via $\mathbf{A}_{2 \mathrm{a}}$ adenosine receptors}

It is shown that intracellular $\mathrm{Ca}^{2+}$ rise triggers glutamate release from astrocytes $(2-6,8)$. As expected, adenosine causes a 2-3-fold increase in glutamate release from cultured hippocampal astrocytes from normal rats and mice (7). A similar increase is obtained with cultured astrocytes from GLT-1 knock-out mice and the glutamate release is not inhibited by the GLT-1 inhibitor dehydrokainic acid or by deleting $\mathrm{Na}^{+}$ from extracellular solution (7). These demonstrate that the glutamate release is not due to reverse transport by transporters including GLT-1. Adenosine-induced glial glutamate release is inhibited by DMPX or $\mathrm{H}-89$, but not by 8-CPT, an agonist of $\mathrm{A}_{1}$ adenosine receptors (7). Additionally, CGS21680 stimulates astrocytic glutamate release; and the effect is inhibited by DMPX, H-89, or the vesicular transport inhibitors brefeldin $\mathrm{A}$ and bafilomycin A1 (Fig. 2). It is concluded from these results that adenosine stimulates vesicular glutamate release from astrocytes via $A_{2 a}$ adenosine receptor involving PKA activation (Fig. 3). Astrocytes contain synaptic proteins such as synaptobrevin II, cellubrevin, syntaxin, and SNAP-25 analogue $(9-11)$. Then, the next important question as to how PKA interacts with those synaptic proteins awaits resolution.

\section{References}

1 Porter JT, McCarthy KD. Hippocampal astrocytes in situ respond to glutamate released from synaptic terminals. J Neurosci. 1996;16:5073-5081.

2 Nedergaard M. Direct signaling from astrocytes to neurons in cultures of mammalian brain cells. Science. 1994;263:17681771.

3 Parpura V, Basarsky TA, Liu F, Jeftinija K, Jeftinija S, Haydon PG. Glutamate-mediated astrocyte-neuron signalling. Nature. 1994;369:744-747.

4 Pasti L, Volterra A, Pozzan T, Carmignoto G. Intracellular calcium oscillations in astrocytes: a highly plastic, bidirectional form of communication between neurons and astrocytes in situ. J Neurosci. 1997;17:7817-7830.

5 Araque A, Sanzgiri RP, Parpura V, Haydon PG. Calcium elevation in astrocytes causes an NMDA receptor-dependent increase in the frequency of miniature synaptic currents in cultured hippocampal neurons. J Neurosci. 1998;18:6822-6829.

6 Bezzi P, Carmignoto G, Pasti L, et al. Prostaglandins stimulates calcium-dependent glutamate release in astrocytes. Nature. 1998;391:281-285.

7 Nishizaki T, Nagai K, Nomura T, et al. A new neuromodulatory pathway with a glial contribution mediated via $\mathrm{A}_{2 \mathrm{a}}$ adenosine receptors. Glia. 2002;39:133-147.

8 Pasti L, Zonta M, Pozzan T, Vicini S, Carmignoto G. Cytosolic calcium oscillations in astrocytes may regulate exocytotic release of glutamate. J Neurosci. 2001;21:477-484.

9 Parpura V, Fang Y, Basarsky T, Jahn R, Haydon PG. Expression of synaptobrevin II, cellubrevin and synataxin but not SNAP-25 in cultured astrocytes. FEBS Lett. 1995;377:489-492.

10 Hepp R, Perraut M, Chasserot-Golaz S, et al. Cultured glial cells express the SNAP-25 analogue SNAP-23. Glia. 1999;27:181187.

11 Maienschein V, Marxen M, Volknandt W, Zimmermann H. A plethora of presynaptic proteins associated with ATP-storing organelles in cultured astrocytes. Glia. 1999;26:233-244. 